\title{
Effects of height and overactivation on a composite nickel-titanium T-loop
}

\author{
Alexandre Ribeiro $^{\mathrm{a}}$, Lidia Martins ${ }^{\mathrm{b}}$, Roberto Silva Junior ${ }^{\mathrm{b}}$, Larry White ${ }^{\mathrm{c}}$, \\ Renato Martins ${ }^{\mathrm{b}, \mathrm{d}, *}$ \\ a Private Practice, Natal, Rio Grande do Norte, Brazil \\ ${ }^{\mathrm{b}}$ Faculdade de Odontologia de Araraquara, Universidade Estadual Paulista-UNESP, Araraquara, Brazil \\ ${ }^{\mathrm{c}}$ Baylor College of Dentistry, Dallas, Texas \\ ${ }^{\mathrm{d}}$ Private Practice, Araraquara, São Paulo, Brazil
}

\section{A R T I C L E I N F O}

\section{Article history:}

Received 30 December 2016

Received in revised form

29 July 2017

Accepted 2 August 2017

\section{Keywords:}

Loops

Alloys

Space Closure

Nickel-titanium

\begin{abstract}
A B S T R A C T
Objective: Evaluate the effect of height and overactivation on the force system produced by composite nickel-titanium T-loops.

Material and Methods: Forty nickel-titanium/stainless steel (SS) T-loops were divided into four groups according to height ( 7 or $6 \mathrm{~mm}$ ) and activation/deactivation protocol $(7 \mathrm{~mm}$ or $7 \mathrm{~mm}$ with $2 \mathrm{~mm}$ of overactivation). An Orthodontic Force Tester recorded the $\mathrm{y}$-axis force and the $\mathrm{x}$-axis moment produced for each $0.5 \mathrm{~mm}$ of deactivation, while the moment(x)-to-force $(y)(\mathrm{M} / \mathrm{F})$ ratio was calculated. The data were analyzed by three analyses of variance of repeated measures to detect differences and interactions between height and protocol on the three variables.

Results: T-loops with a height of $6 \mathrm{~mm}$ produced higher forces $(2.97 \mathrm{~N}$ vs. $2.66 \mathrm{~N})$ than those of $7 \mathrm{~mm}$. The moments were similar, whereas the $\mathrm{M} / \mathrm{F}$ was larger for the $7-\mathrm{mm}$ loops (5.76 $\mathrm{mm}$ vs. $4.92 \mathrm{~mm}$ ). The conventional activation produced higher forces (2.99 N vs. $2.64 \mathrm{~N})$, higher moments (16.2 Nmm vs. 13.59 $\mathrm{Nmm}$ ) but the same $\mathrm{M} / \mathrm{F}$. The $\mathrm{M} / \mathrm{F}$ showed an interaction with deactivation.

Conclusion: The 6-mm-high T-loops produced higher forces, but lower M/F. The conventional protocol produced higher forces and moments. The M/F ratio was similar for both protocols, but overactivation produced a nearly constant $\mathrm{M} / \mathrm{F}$ throughout deactivation. The use of a 7-mm-high overactivated segmented nickel-titanium loop might improve the performance of orthodontic space closure.
\end{abstract}

(C) 2017 World Federation of Orthodontists.

\section{Introduction}

Ever since T-loops were proposed for orthodontic space closure [1], several modifications have developed to improve their mechanical properties. Modifications on the loop height, preactivation, wire dimension, alloy type, and degree of horizontal activation have been tested to improve their use. Nevertheless, horizontal activation that would allow complete closure of premolar extraction spaces with a single activation would further improve the efficiency of T-loops. Taller T-loops allow larger activations [2], but loop heights are limited by vestibular depth, and such loops require reactivation after 3 to $4 \mathrm{~mm}$ of space closure because the force decreases and moment(x)-to-force $(\mathrm{y})(\mathrm{M} / \mathrm{F})$ ratio rises excessively [2].

Fundação de Amparo à Pesquisa do Estado de São Paulo (Fapesp), Process number:2011/12943-1.

* Corresponding author: Faculdade de Odontologia de Araraquara, Universidade Estadual Paulista-UNESP, Jacksonville University, School of Orthodontics, Rua Carlos Gomes 2158, Araraquara 14801340, Brazil.

E-mail address: de_renatopmartins@hotmail.com (R. Martins).
T-loops made of shape memory alloys will experience a stressinduced martensitic transformation (SIMT) and produce a pseudo-plateau ${ }^{1}$ of force on deactivation, which allows greater activations without significant change of force during deactivation for en masse retraction [3]. However, the load-deflection graph of a nickel-titanium material that underwent SIMT displays a characteristic shape on unloading and a sudden drop of force when the load is removed before the pseudo-plateau is reached [4] (Fig. 1). This characteristic suggests that overactivated nickel-titanium loops might improve the performance of orthodontic appliances as previously suggested [5,6]. Even though there have been other reports on nickel-titanium T-loops [3,7-9], no study has yet investigated the effects of overactivation to

\footnotetext{
${ }^{1}$ In this manuscript, the near-to constant force described on a load/deflection graph during reverse stress induced transformation of a shape memory alloy was termed pseudo-plateau because the term plateau would point toward a completely flat shape, which does not occur normally.
} 


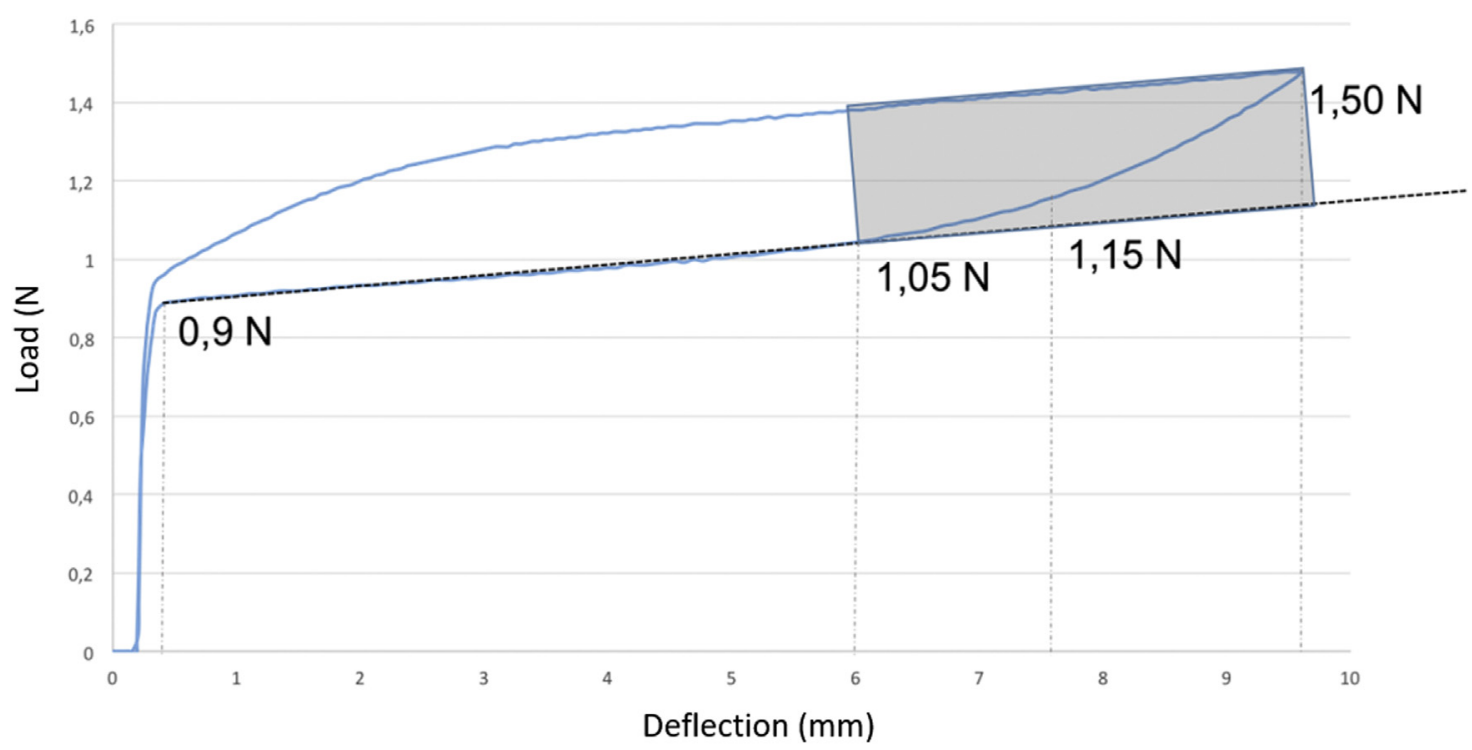

Fig. 1. The load-deflection graph of a closed-coil spring depicting a sudden drop of force immediately after the start of the reverse SIMT and just before the description of a pseudoplateau by the graph.

eliminate the sudden drop of force at the beginning of the reverse transformation.

Another feature not yet described with nickel-titanium T-loops is the effect of loop height on the force system. Previous studies have tested 8.45-mm nickel-titanium T-loops [7-9], whose excessive heights would make clinical application difficult. Thus, to have clinically useful T-loop designs will require knowledge about all effects of loop sizes, but nickel-titanium's properties might cause one to expect loop size to have negligible effects in contrast to betatitanium T-loops, whose loop heights affected the force, moments, and $\mathrm{M} / \mathrm{F}$ ratios $[1,10-12]$.

Thus, the aim of this study was to investigate the influence of loop height and overactivation of nickel-titanium T-loops on the created force system.

\section{Materials and methods}

Forty T-loop springs, with dimensions of $10 \mathrm{~mm}$ in length and $20 \mathrm{~mm}$ in height (Fig. 2), were produced of $0.018 \times 0.025$-inch superelastic nickel-titanium (Neo Sentalloy, F 100; GAC

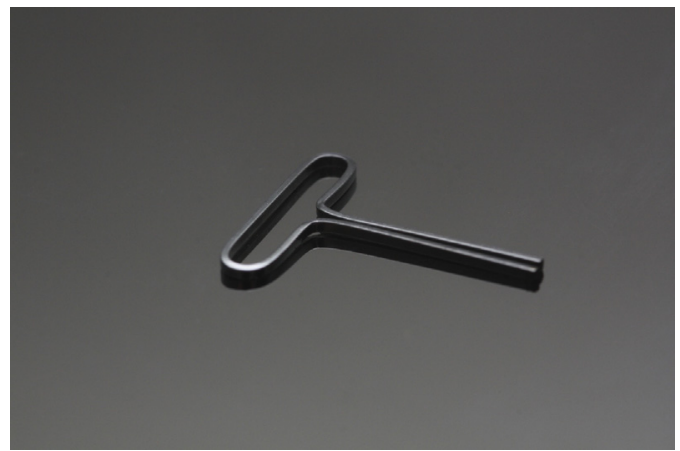

Fig. 2. Nickel-titanium T-loop used in this investigation before the use of the crimpable tubes to determine its height.
International, New York, NY) using a SS template at a temperature of $510^{\circ} \mathrm{C}$ for 9 minutes and cooled under running water.

The loops were divided into two groups $(n=20)$ and made into heights of 6 or $7 \mathrm{~mm}$ by adjusting the loops' vertical extensions to two 0.022-inch crimped cross tubes (Morelli Ortodontia, Sorocaba, Brazil) before the tubes were crimped, a cinch bend was applied to the loop using a nickel-titanium Cinch-Bend Plier (IV-Tech, Seoul, Korea) (Fig. 3A). Each group was further divided into two groups according to the amount of activation/deactivation that they would be subjected ( $7 \mathrm{~mm}$ or $9 \mathrm{~mm}$ ). The four groups were defined as Act6, Over6 (6 $\mathrm{mm}$ of height with conventional activation and overactivation, respectively), Act7, and Over7 (7 mm of height with conventional activation and overactivation, respectively). The base wires were of $0.017 \times 0.025$-inch stainless steel (SS) wire (Nubryte Wire; Dentsply International, New York, NY) that were crimped into the cross tubes and given a preactivation curvature of $12 \mathrm{~mm}$ (Fig. 3A and 3B). A cinch bend was carefully made with a bird peak pliers to ensure the wire would not slide trough the crimped crossed tube with activation of the loop (Fig. 3A).

The Orthodontic Force Tester (OFT) [13] simulated loop activation. Two 0.018-inch first upper self-ligating premolar brackets (Innovation R; Dentsply International) were soldered passively to each other to extensions connected to the two load cells of the OFT (Fig. 4).

To ensure centralization of the spring and standardized activations at $23 \mathrm{~mm}$ of interbracket distance (IBD), felt-tip pen markings were made $7 \mathrm{~mm}$ from the center of the loop at both ends of the base wires (before preactivation), defining $9 \mathrm{~mm}$ of activation in a 23-mm interbracket distance. A cinch bend was made with a bird beak pliers at the exact bracket distance from the felt-tip markings to act as a stop and ensure the loop would be held in place. Groups Act6 and Act7 were deactivated from $23 \mathrm{~mm}$ to $18 \mathrm{~mm}$ (or from $9 \mathrm{~mm}$ of the loop's activation to $4 \mathrm{~mm}$ ), whereas groups Over6 and Over7 were given $2 \mathrm{~mm}$ of overactivation (Fig. 4). The scale built in the OFT structure with its adjustment screws allowed the brackets to be moved apart $2 \mathrm{~mm}$, to a $25-\mathrm{mm}$ IBD, and then returned to their original position of $23 \mathrm{~mm}$ IBD before data were collected for that group (Fig. 5A). The IBD distances were carefully verified with 

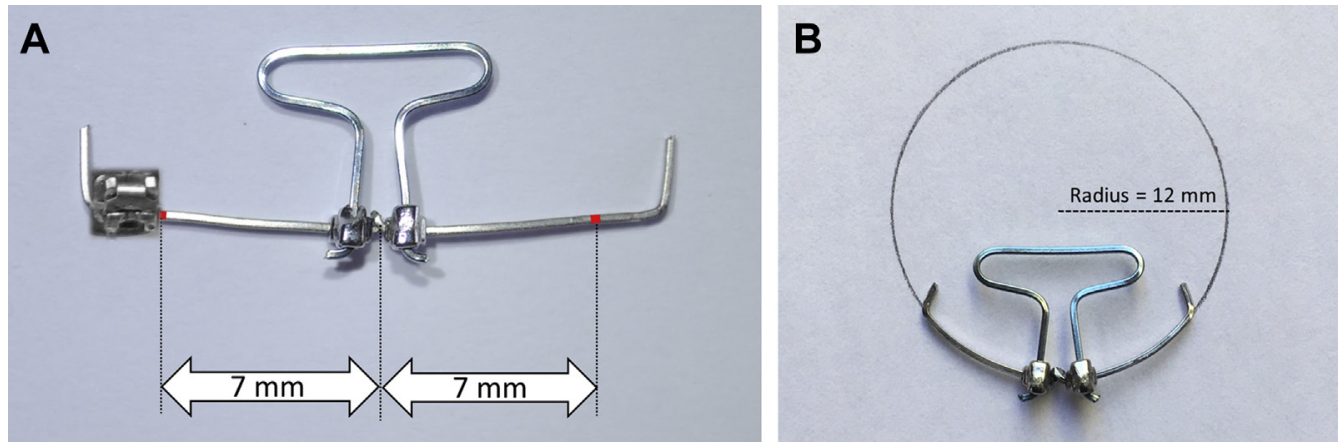

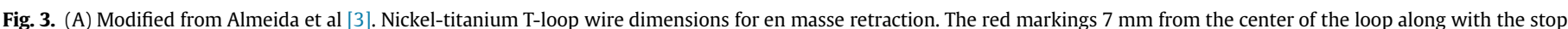

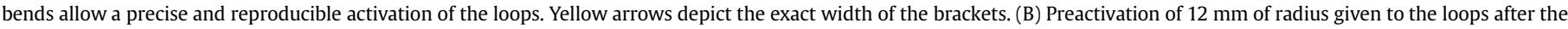
markings and stops were bent.

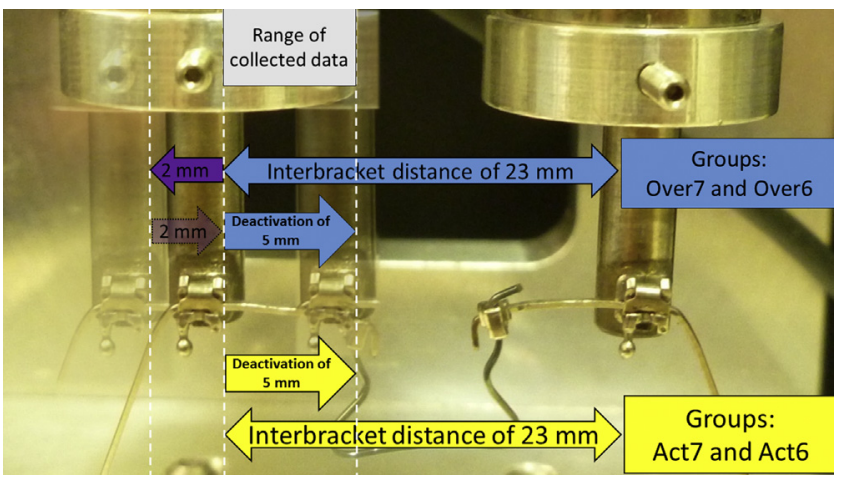

Fig. 4. Regimen of the activation and deactivation of both "Act" and "Over" groups, in yellow and blue, respectively. Purple arrows show the overactivation of the "Over" groups before data were collected.

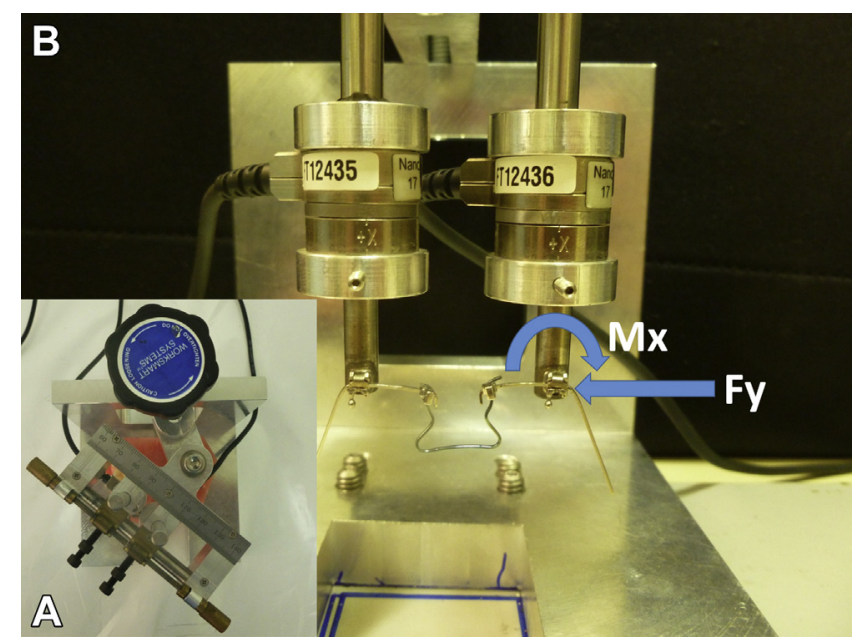

Fig. 5. (A) The OFT scale, as seen from above the OFT. (B) A composed nickel-titanium T-loop being tested with the depiction of the forces and moments collected by the OFT's dedicated software.

digital calipers (Mitutoyo Co, Kawasaki, Japan) before data were collected during $5 \mathrm{~mm}$ of deactivation for both groups, from an IBD of $23 \mathrm{~mm}$ to $18 \mathrm{~mm}$ (or from $9 \mathrm{~mm}$ to $4 \mathrm{~mm}$ of loop activation).

The force produced in the $\mathrm{y}$-axis and the moment produced in the $\mathrm{x}$-axis were recorded (Fig. 5B) for each $0.5 \mathrm{~mm}$ of spring deactivation by the OFT software and transferred to a Microsoft Excel spreadsheet 2011 (Office 2011; Microsoft, Redmond, WA),
Table 1

Mean estimates of force $(\mathrm{N})$ and $\mathrm{M} / \mathrm{F}$ ratios, standard deviations, and confidence intervals of the T-loops in relation to their height $(\mathrm{mm})$, regardless of the deactivation protocol used

\begin{tabular}{llllll}
\hline & Height & Average & SD & \multicolumn{2}{l}{ 95\% confidence interval } \\
\cline { 5 - 6 } & & & & Lower limit & Upper limit \\
\hline Force $(\mathrm{N})$ & 6 & 2.97 & 0.26 & 2.88 & 3.07 \\
$\mathrm{M} / \mathrm{F}$ & 7 & 2.66 & 0.30 & 2.56 & 2.7 \\
& 6 & 4.96 & 0.51 & 4.78 & 5.13 \\
& 7 & 5.76 & 0.38 & 5.58 & 5.94 \\
\hline
\end{tabular}

M/F, moment(x)-to-force(y) ratio; SD, standard deviation.

Table 2

Mean estimates of force $(\mathrm{N})$ and moments produced $(\mathrm{Nmm})$, standard deviations, and confidence intervals of the T-loops in relation to its deactivation protocol, regardless of the height variation

\begin{tabular}{llrrrr}
\hline & Deactivation protocol & Mean & SD & \multicolumn{2}{c}{ 95\% confidence interval } \\
\cline { 5 - 6 } & & & & Lower limit & Upper limit \\
\hline Force (N) & Act & 2.99 & 0.26 & 2.89 & 3.09 \\
& Overact & 2.64 & 0.28 & 2.54 & 2.73 \\
\multirow{2}{*}{ Moment (Nmm) } & Act & 16.20 & 0.83 & 15.76 & 16.64 \\
& Overact & 13.59 & 1.12 & 13.16 & 14.03 \\
\hline
\end{tabular}

SD, standard deviation.

with the calculated $\mathrm{M} / \mathrm{F}$ ratio. The OFT was maintained inside a thermally isolated glove-box with an electronic temperature control at $37^{\circ} \mathrm{C}$ made especially for the study.

The Kolmogorov-Smirnov test verified the normality of the variables, which allowed a two-level analysis of variance of repeated measures for detecting the differences on the horizontal forces, moments, and $\mathrm{M} / \mathrm{F}$ ratios caused by the overactivation and loop height, as well as any possible interaction between these two factors. Statistical analysis used SPSS software version 20.0 (SPSS Inc., Chicago, IL).

The Mauchly test showed that sphericity was violated in all the variables tested, and the degrees of freedom were corrected by the Huynh-Feldt epsilon to adjust the F values of the tests.

\section{Results}

T-loops of different heights produced different forces $(P<$ $0.001)$. The T-loops with heights of $6 \mathrm{~mm}$ produced greater forces $(2.97 \mathrm{~N})$ than those of $7 \mathrm{~mm}(2.66 \mathrm{~N})$ (Table 1$)$. Also, deactivation forces from the T-loops differed $(P<0.001)$. The two tested deactivation protocols produced significantly different forces; the conventional activation $(2.99 \mathrm{~N})$ produced greater forces than the overactivated T-loops $(2.64 \mathrm{~N})(P<0.001)$ (Table 2$)$. An interaction 
Fy (N)
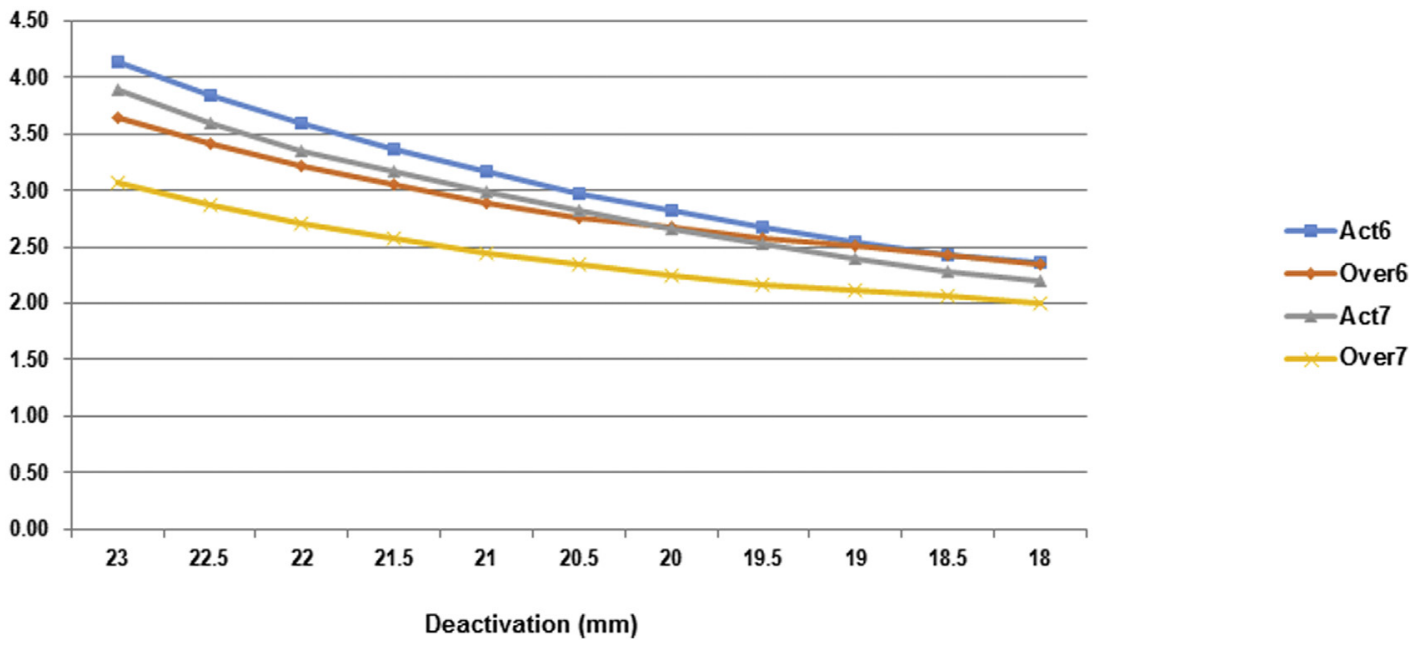

Fig. 6. Horizontal forces, in newtons, of the four tested groups at each $0.5 \mathrm{~mm}$ of deactivation.

between the variables of deactivation and height $(P=0.01)$, as well as deactivation and horizontal activation also occurred $(P<0.001)$ (Fig. 6).

The height of the loop did not influence the moments produced $(P=0.11)$ but the deactivation $\operatorname{did}(P<0.001)$. The conventional $7 \mathrm{~mm}$ of activation produced greater moments $(16.2 \mathrm{Nmm})$ than overactivated T-loops (13.59 Nmm) (Table 2). No interactions existed between the variables in the moments produced (Fig. 7).

The 7-mm T-loops produced a larger $\mathrm{M} / \mathrm{F}$ ratio than the $6 \mathrm{~mm}$ (5.76 and $4.92 \mathrm{~mm}$, respectively) $(P<0.001)$ (Table 1$)$, and the deactivation of the loops also produced different $\mathrm{M} / \mathrm{F}$ ratios $(P<$ 0.001 ), which ranged from $5.07 \mathrm{~mm}$ to $5.44 \mathrm{~mm}$. The protocol of deactivation (horizontal activation) did not influence the $\mathrm{M} / \mathrm{F}$ ratios, but showed an interaction for both the deactivation $(P<0.001)$ and the height $(P=0.003)$. However, no interaction occurred among the three variables $(P=0.64)$ (Fig. 8$)$.

\section{Discussion}

As expected, the 6-mm T-loops produced larger horizontal forces than the 7-mm one. Previous investigations established an inverse relationship between the height increase and the force produced in beta-titanium T-loops [1,10-12]. The increase from $6 \mathrm{~mm}$ to $7 \mathrm{~mm}$ of height in an SS T-loop produces a decrease in 10\% of the force [12], which is similar to what occurred in our composed nickel-titanium T-loop (Table 1). When produced exclusively from SS or beta-titanium, this inverse relationship is relatively linear, but the superelastic properties of nickel-titanium obviate linear behavior. The performance of compound T-loops depends on the concentrations of activation stresses and their ability to induce martensitic transformations in parts of the loop.

The forces produced in all tested nickel-titanium T-loops reduced with deactivation as it occurs in any spring [12,14-16]. The load-deflection rate of these superelastic T-loops did not display a perfectly horizontal shape on deactivation but rather a declining pseudo-plateau (Table 3 and Fig. 6). Additionally, the beginning of the reverse transformation from the SIMT that occurs at the beginning of the deactivation in coil, or loop spring, produces a sudden drop in force before the previously mentioned pseudoplateau [4] (Fig. 1). This is the reason we overactivated the T-loops $2 \mathrm{~mm}$ and collected data only after the $2 \mathrm{~mm}$ of deactivation, which eliminated some of the sudden drop in force before the pseudo-plateau. Moreover, overactivating shape memory springs caused the average force of the pseudo-plateau on deactivation to

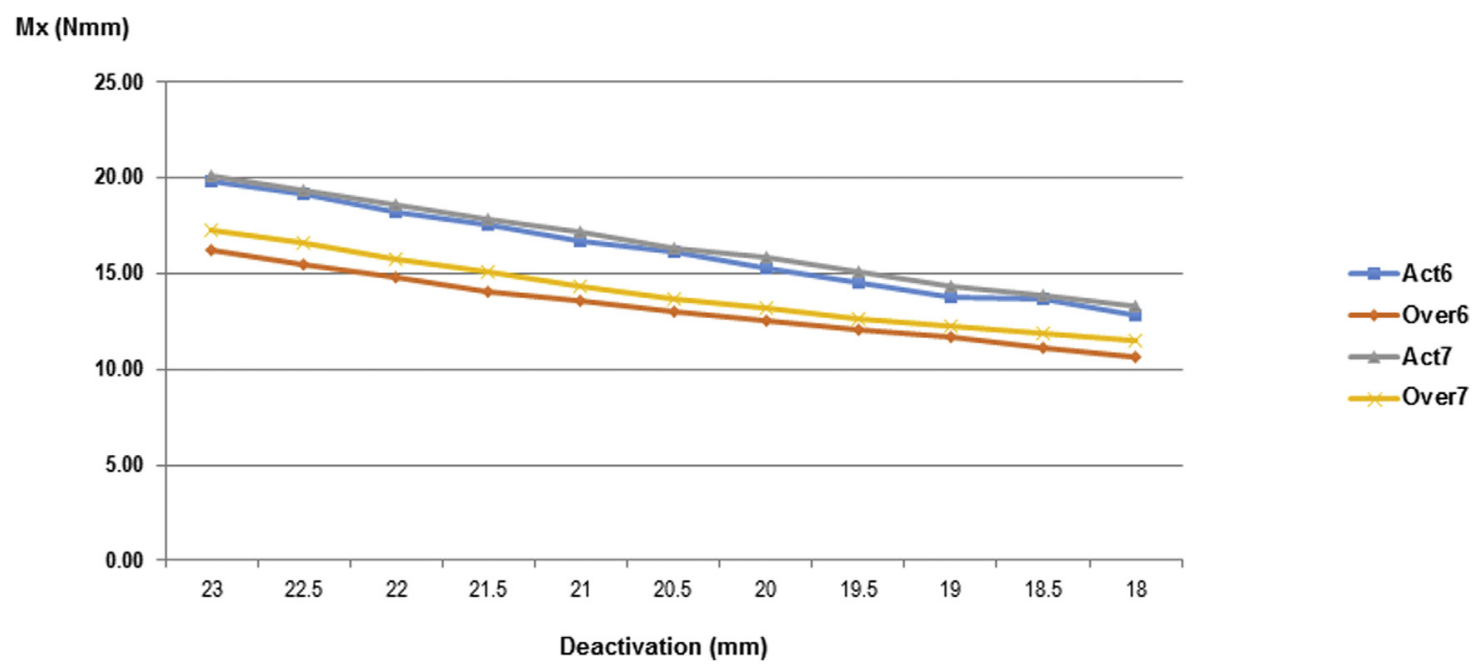

Fig. 7. Moments produced on the x-axis, in Newton-millimeters, of the four tested groups at each 0.5 mm of deactivation. 


\section{$\mathrm{Mx} / \mathrm{Fy}(\mathrm{mm})$}

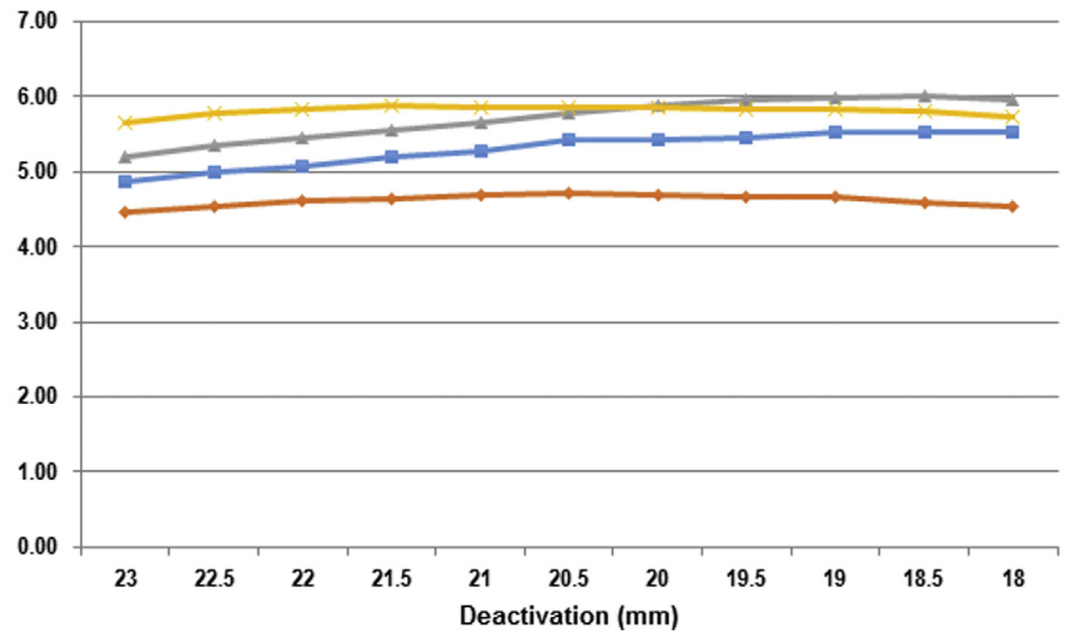

Fig. 8. M/F ratio produced, in millimeters, of the four tested groups at each $0.5 \mathrm{~mm}$ of deactivation.

Table 3

Averages of force $(\mathrm{N})$ and standard deviations $(\mathrm{sd})$ per $0.5 \mathrm{~mm}$ of deactivation protocol produced per group

\begin{tabular}{|c|c|c|c|c|c|c|c|c|}
\hline \multirow{2}{*}{$\begin{array}{l}\text { Deactivation } \\
\text { protocol }\end{array}$} & \multicolumn{2}{|l|}{ Act6 } & \multicolumn{2}{|l|}{ Over6 } & \multicolumn{2}{|l|}{ Act7 } & \multicolumn{2}{|l|}{ Over7 } \\
\hline & Force & sd & Force & sd & Force & sd & Force & sd \\
\hline 23 & 4.13 & 0.81 & 3.65 & 0.23 & 3.90 & 0.67 & 3.07 & 0.23 \\
\hline 22.5 & 3.84 & 0.35 & 3.41 & 0.22 & 3.59 & 0.27 & 2.87 & 0.21 \\
\hline 22 & 3.60 & 0.34 & 3.22 & 0.20 & 3.36 & 0.25 & 2.71 & 0.19 \\
\hline 21.5 & 3.37 & 0.34 & 3.05 & 0.17 & 3.17 & 0.25 & 2.57 & 0.16 \\
\hline 21 & 3.17 & 0.31 & 2.90 & 0.16 & 2.99 & 0.24 & 2.45 & 0.15 \\
\hline 20.5 & 2.98 & 0.30 & 2.76 & 0.16 & 2.82 & 0.23 & 2.34 & 0.14 \\
\hline 20 & 2.82 & 0.27 & 2.67 & 0.18 & 2.66 & 0.19 & 2.25 & 0.14 \\
\hline 19.5 & 2.68 & 0.26 & 2.58 & 0.18 & 2.52 & 0.18 & 2.17 & 0.14 \\
\hline 19 & 2.54 & 0.29 & 2.51 & 0.19 & 2.39 & 0.17 & 2.11 & 0.14 \\
\hline 18.5 & 2.43 & 0.23 & 2.42 & 0.19 & 2.29 & 0.16 & 2.06 & 0.15 \\
\hline 18 & 2.36 & 0.25 & 2.34 & 0.19 & 2.20 & 0.15 & 2.00 & 0.17 \\
\hline
\end{tabular}

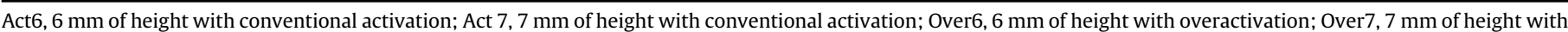
overactivation.

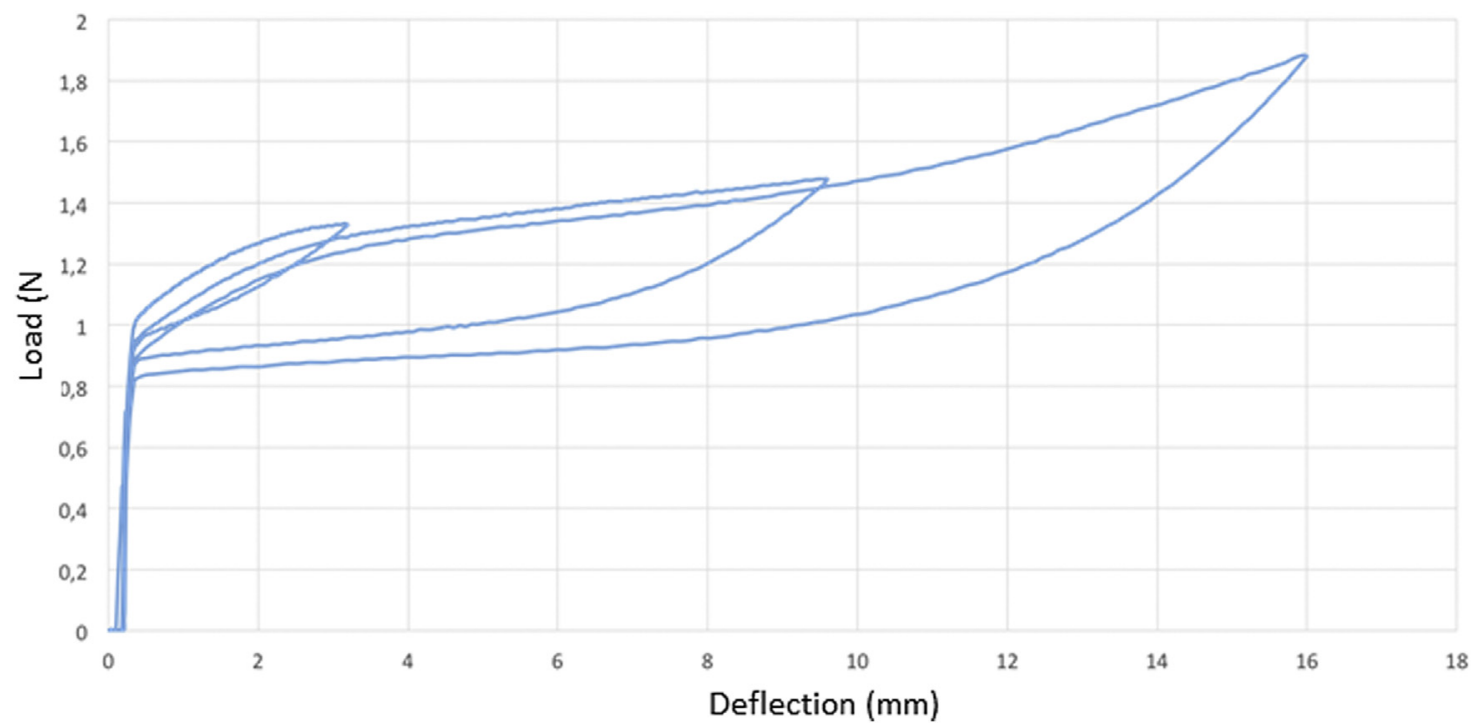

Fig. 9. Load-deflection graph of a closed-coil nickel-titanium spring showing the decrease of the force produced on deactivation given larger initial activations. 
Table 4

Averages of moment $(\mathrm{Nmm})$ and standard deviations per $0.5 \mathrm{~mm}$ of deactivation protocol produced per group

\begin{tabular}{|c|c|c|c|c|c|c|c|c|}
\hline \multirow{2}{*}{$\begin{array}{l}\text { Deactivation } \\
\text { protocol, mm }\end{array}$} & \multicolumn{2}{|l|}{ Act6 } & \multicolumn{2}{|l|}{ Over6 } & \multicolumn{2}{|l|}{ Act7 } & \multicolumn{2}{|l|}{ Over7 } \\
\hline & Moment & s.d. & Moment & s.d. & Moment & s.d. & Moment & s.d. \\
\hline 23 & 19.82 & 1.00 & 16.18 & 1.26 & 20.11 & 2.86 & 17.30 & 1.16 \\
\hline 22.5 & 19.11 & 1.02 & 15.42 & 1.09 & 19.37 & 2.80 & 16.56 & 1.11 \\
\hline 22 & 18.22 & 1.05 & 14.77 & 1.01 & 18.57 & 2.66 & 15.76 & 1.17 \\
\hline 21.5 & 17.52 & 1.00 & 14.07 & 0.97 & 17.80 & 0.69 & 15.05 & 1.12 \\
\hline 21 & 16.73 & 1.01 & 13.57 & 1.06 & 17.13 & 0.64 & 14.32 & 1.10 \\
\hline 20.5 & 16.17 & 1.02 & 13.00 & 1.19 & 16.27 & 0.72 & 13.66 & 1.00 \\
\hline 20 & 15.25 & 1.02 & 12.52 & 1.40 & 15.80 & 0.55 & 13.16 & 0.95 \\
\hline 19.5 & 14.52 & 1.13 & 12.02 & 1.54 & 15.10 & 0.50 & 12.65 & 0.91 \\
\hline 19 & 13.61 & 1.35 & 11.67 & 1.67 & 14.31 & 0.51 & 12.27 & 0.75 \\
\hline 18.5 & 13.61 & 1.34 & 11.14 & 1.74 & 13.88 & 0.48 & 11.90 & 0.87 \\
\hline 18 & 12.82 & 0.98 & 10.65 & 1.90 & 13.28 & 0.35 & 11.45 & 0.85 \\
\hline
\end{tabular}

Act6, $6 \mathrm{~mm}$ of height with conventional activation; Act 7, $7 \mathrm{~mm}$ of height with conventional activation; Over6, $6 \mathrm{~mm}$ of height with overactivation; Over7, $7 \mathrm{~mm}$ of height with overactivation; s.d., standard deviation.

diminish $[4,6,17,18]$ (Fig. 9) as occurred in this investigation, where overactivation of the loops produced lower forces.

The height of the T-loops did not affect the intensity of the moments. These results differ from those of beta-titanium T-loops, where the moments decrease as loop height increases [11,12]. Increased flexibility from added wire length with height decreases moments. This did not occur with the superelastic T-loops we tested. The moments also decreased as the nickel-titanium T-loops deactivated, similar to beta-titanium T-loops.

The reduction in moments with deactivation of the nickeltitanium T-loops was similar to beta-titanium T-loops [1,11,19-21] (Fig. 7 and Table 4). The force of beta-titanium T-loops, in contrast, decreases faster than the moment with deactivation $[1,11,19-21]$. This study found a near constant $M / F$ ratio on the T-loops as they deactivated (Table 5 and Fig. 8), which offers clinical promise for space closure, because the centers of rotation of a tooth or group of teeth will stay reasonably constant with forces high enough for en masse retraction. Currently, clinicians can achieve this only with frictionless mechanics with extended hooks.

The moments were influenced by the deactivation protocol. As previously described, this study tested the overactivation group for the reduction in initial horizontal forces from T-loops and allowed the use of a superelastic pseudo-plateau. Overactivation not only produced lower initial forces but also may have attenuated the moments, as this procedure clears the sudden drop of force and moments from beginning of the martensitic reverse transformation from the actual clinical use.

Table 5

Averages of $\mathrm{M} / \mathrm{F}$ ratio $(\mathrm{mm})$ and standard deviations per $0.5 \mathrm{~mm}$ of deactivation protocol produced per group

\begin{tabular}{|c|c|c|c|c|c|c|c|c|}
\hline \multirow[t]{2}{*}{ Deactivation protocol } & \multicolumn{2}{|l|}{ Act6 } & \multicolumn{2}{|c|}{ Over6 } & \multicolumn{2}{|l|}{ Act7 } & \multicolumn{2}{|c|}{ Over7 } \\
\hline & $\mathrm{M} / \mathrm{F}$ & s.d. & $\mathrm{M} / \mathrm{F}$ & s.d. & $\mathrm{M} / \mathrm{F}$ & s.d. & $\mathrm{M} / \mathrm{F}$ & s.d. \\
\hline 23 & 4.86 & 0.41 & 4.46 & 0.31 & 5.32 & 0.38 & 5.66 & 0.38 \\
\hline 22.5 & 5.00 & 0.39 & 4.54 & 0.27 & 5.35 & 0.37 & 5.79 & 0.36 \\
\hline 22 & 5.08 & 0.37 & 4.61 & 0.25 & 5.45 & 0.45 & 5.84 & 0.35 \\
\hline 21.5 & 5.19 & 0.41 & 4.64 & 0.23 & 5.56 & 0.49 & 5.87 & 0.34 \\
\hline 21 & 5.27 & 0.43 & 4.70 & 0.29 & 5.66 & 0.46 & 5.87 & 0.37 \\
\hline 20.5 & 5.43 & 0.47 & 4.72 & 0.38 & 5.69 & 0.55 & 5.85 & 0.41 \\
\hline 20 & 5.43 & 0.48 & 4.70 & 0.42 & 5.89 & 0.39 & 5.86 & 0.39 \\
\hline 19.5 & 5.45 & 0.52 & 4.67 & 0.47 & 5.95 & 0.40 & 5.84 & 0.39 \\
\hline 19 & 5.52 & 0.54 & 4.66 & 0.53 & 5.93 & 0.38 & 5.84 & 0.38 \\
\hline 18.5 & 5.52 & 0.51 & 4.60 & 0.57 & 6.01 & 0.40 & 5.81 & 0.42 \\
\hline 18 & 5.52 & 0.52 & 4.54 & 0.67 & 5.97 & 0.35 & 5.74 & 0.40 \\
\hline
\end{tabular}

Act6, $6 \mathrm{~mm}$ of height with conventional activation; Act 7, $7 \mathrm{~mm}$ of height with conventional activation; M/F, moment(x)-to-force(y); Over6, $6 \mathrm{~mm}$ of height with overactivation; Over7, $7 \mathrm{~mm}$ of height with overactivation; s.d., standard deviation.
The height of the loops definitely affected the $\mathrm{M} / \mathrm{F}$ ratio. These results confirm other studies, which established that $M / F$ varies directly with loop height $[10,11]$. However, this study discovered only a small difference (less than $1 \mathrm{~mm}$ ), which may enable a reduction in the height of the loop. In certain situations this could increase patient comfort without losing control. Even though overactivation did not influence the $\mathrm{M} / \mathrm{F}$ produced in total, it produced a different behavior with deactivation, shown by the significant interaction between the overactivation and the changes in $\mathrm{M} / \mathrm{F}$ as the loops closed. The results show that $\mathrm{M} / \mathrm{F}$ remained more constant in the overactivated loops than in the conventionally activated ones (Fig. 8), with the latter resembling the behavior of beta-titanium T-loops [1], in a subtler manner.

It appears from the tested groups that a 7-mm-high overactivated loop could bring a much more constant $\mathrm{M} / \mathrm{F}$ for en masse space closure. However, the low force produced toward the end of its deactivation might be an issue. The literature has shown that an increase in the width of the wire used for the loop can increase the horizontal force produced [3], and could compensate that effect. We used a $0.018 \times 0.025$-inch nickel-titanium wire for the loop based on that data, but apparently further increase in wire size would be necessary to increase the force levels. Further research may be necessary to produce and activate similar nickel-titanium composite loops that would be functional in clinical orthodontics. In this investigation, an IBD compatible to a segmented approach was used to test height and activation protocols. Future investigations could allow its use in a continuous archwire. Although overactivation provides a virtually constant $\mathrm{M} / \mathrm{F}$ ratio, it may not be enough when greater root control is needed. Such patients would need an increase in the moments produced by T-loops without a significant alteration of the horizontal force. One possible alternative could be an increase the preactivation of the base wire, which offers an negligible effect when done in combination with nickeltitanium T-loops. Additional limitations of this article include the fact that not every nickel-titanium alloy behaves equally and that the load systems found by this investigation were registered at the middle of the brackets and not at the axis of resistance of the teeth.

\section{Conclusions}

1. Six-millimeter-high T-loops produced higher forces than those of $7 \mathrm{~mm}$. The moments were similar between the two heights while the $\mathrm{M} / \mathrm{F}$ ratio increased with the loop height.

2. The conventional activation protocol produced higher forces and moments than the overactivation protocol.

3. Both the protocols produced, on average, the same $M / F$ ratio. The overactivation loops, however, produced an almost constant $\mathrm{M} / \mathrm{F}$ ratio throughout deactivation whereas the conventional activation produced an increasing $\mathrm{M} / \mathrm{F}$ ratio with deactivation.

\section{References}

[1] Burstone CJ, Koenig HA. Optimizing anterior and canine retraction. Am J Orthod 1976;70:1-19.

[2] Viecilli RF. Self-corrective T-loop design for differential space closure. Am J Orthod Dentofacial Orthop 2006;129:48-53.

[3] Almeida L, Ribeiro A, Parsekian Martins R, Viecilli R, Parsekian Martins L. Nickel titanium T-loop wire dimensions for en masse retraction. Angle Orthod 2016;86:810-7.

[4] Vieira CIV, Reis J, Vaz LG, Martins LP, Martins RP. Deformation of nickeltitanium closed coil springs: an in vitro study. Dental Press J Orthod 2017;22:38-46.

[5] Manhartsberger C, Seidenbusch W. Force delivery of Ni-Ti coil springs. Am J Orthod Dentofacial Orthop 1996;109:8-21.

[6] Vieira CI, Caldas SG, Martins LP, Martins RP. Superelasticity and force plateau of nickel-titanium springs: an in vitro study. Dental Press J Orthod 2016;21:46-55. 
[7] Keng FY, Quick AN, Swain MV, Herbison P. A comparison of space closure rates between preactivated nickel-titanium and titanium-molybdenum alloy T-loops: a randomized controlled clinical trial. Eur J Orthod 2012;34:33-8.

[8] Kum M, Quick A, Hood JA, Herbison P. Moment to force ratio characteristics of three Japanese NiTi and TMA dosing loops. Aust Orthod J 2004;20:107-14.

[9] Rose D, Quick A, Swain M, Herbison P. Moment-to-force characteristics of preactivated nickel-titanium and titanium-molybdenum alloy symmetrical T-loops. Am J Orthod Dentofacial Orthop 2009;135:757-63.

[10] Martins RP, Buschang PH, Martins LP, Gandini Jr LG. Optimizing the design of preactivated titanium T-loop springs with Loop software. Am J Orthod Dentofacial Orthop 2008;134:161-6.

[11] Faulkner MG, Fuchshuber P, Haberstock D, Mioduchowski A. A parametric study of the force/moment systems produced by T-loop retraction springs. J Biomech 1989;22:637-47.

[12] Chen J, Markham DL, Katona TR. Effects of T-loop geometry on its forces and moments. Angle Orthod 2000;70:48-51.

[13] Chen J, inventor. Apparatus and method for measuring orthodontic force applied by an orthodontic appliance. US 6120287. September 19, 2000.
[14] Hoenigl KD, Freudenthaler J, Marcotte MR, Bantleon HP. The centered T-loop-a new way of preactivation. Am J Orthod Dentofacial Orthop 1995;108:149-53.

[15] Martins RP, Buschang PH, Viecilli R, dos Santos-Pinto A. Curvature versus V-bends in a group B titanium T-loop spring. Angle Orthod 2008;78:517-23.

[16] Kuhlberg A. Force systems from T-loop orthodontic space closure springs: The effects of asymmetric placement and angulation on the alpha-beta moment differential, University of Connecticut School of Dental Medicine; 1992.

[17] Burstone CJ, Qin B, Morton JY. Chinese NiTi wire-a new orthodontic alloy. Am J Orthod 1985;87:445-52.

[18] Magno AF, Monini Ada C, Capela MV, Martins LP, Martins RP. Effect of clinical use of nickel-titanium springs. Am J Orthod Dentofacial Orthop 2015;148:76-82.

[19] Burstone CJ, van Steenbergen E, Hanley KJ. Modern edgewise mechanics \& the segmented arch technique. Glendora, CA: Ormco Co.; 1995.

[20] Caldas SG, Martins RP, Galvao MR, Vieira CI, Martins LP. Force system evaluation of symmetrical beta-titanium T-loop springs preactivated by curvature and concentrated bends. Am J Orthod Dentofacial Orthop 2011;140:e53-8.

[21] Manhartsberger C, Morton JY, Burstone CJ. Space closure in adult patients using the segmented arch technique. Angle Orthod 1989;59:205-10. 